\title{
Mevsimlik Olmayan Box-Jenkins Modellerinde İki Aşamalı Yapay Sinir Ağlarının Kullanılması
}

\author{
*Gültekin Çağ 11 \\ *Sakarya Üniversitesi, Mühendislik Fakültesi, Endüstri Mühendisliği Bölümü, Sakarya, Türkiye
}

\section{$\ddot{O} \mathbf{z}$}

Bu çalışma Box-Jenkins ile tahmin yapmak için, sözkonusu tekniğe ait belirli adımlarda alternatif olarak Yapay Sinir Ağları Yapay Zeka tekniğini kullanmaya yöneliktir. Bu amaçla içinde eğitilmiş ağları kullanan bir bilgisayar algoritması geliştirilmiştir. Geliştirilen algoritmanın sonuçlarının kıyaslanabilmesi için, Box-Jenkins tekniğini bilinen (klasik) şekliyle kullanan programlar içinden Statistica for Windows seçilmiştir. Hazırlanan test setleri Statistica programı ve geliştirilen algoritma ile ayrı ayrı işleme sokulmuş ve elde edilen sonuçlar karşılaştırılmıştır.

Anahtar Kelimeler: Tahmin, Box-Jenkins Tahmin Yöntemi, Yapay Sinir Ağları, Parametre Tahmini

\section{Two Phased Artificial Neural Network Learning Embedded into Box- Jenkins Modelling for Non-Seasonal Data}

\begin{abstract}
This study is about making forecasts with Box-Jenkins method using Artificial Neural Network, Artificial Intelligence technique in specific steps. For this purpose an algorithm is developed which is using trained networks. For comparison of developed algorithm's results, Statistica for windows is choosen from programs using BoxJenkins technique in common (classic) way. Prepared test sets, are put in process seperately with Statistica program and developed algorithm, and the obtained results are compared.
\end{abstract}

Keywords: Forecasting, Box-Jenkins Forecasting Technique, Artificial Neural Network, Parameter Estimation

\section{Giriş}

Tahmin; geçmişten elde edilen değerlerle, geçmişin ve geleceğin değerlerinin belirlenmesi olarak tanımlanabilir. Tahmin işleminin en önemli varsayımı, incelenen verilerin geçmişteki seyrinin, gelecekte de aynı şekilde devam edeceğidir. Amaç geçmiş ve gelecek dönemler için tahmin yapmak olduğuna göre, incelenen verilerin önceki dönemlere ait seyri ve özellikleri doğru bir şekilde ortaya konması ve yine verilere uygun tahmin tekniğinin doğru bir şekilde seçilmesi gerekir.

\subsection{Box-Jenkins Tahmin Tekniği}

Genel olarak tahmin kavramı, insanlık tarihi kadar eskidir. Bilimsel gelişmelerle birlikte, yapılan tahminler için bazı teknikler geliştirilmiştir; Regresyon Analizi, Ekonometrik Teknikler, Hareketli Ortalamalar, Üstel Düzeltme Teknikleri, Box-Jenkins Tekniği bunlardan bazılarıdır. BoxJenkins tekniği, diğerlerine göre en son geliştirilen tahmin tekniklerden birisidir. $\mathrm{Bu}$ nedenle diğer tekniklerin olumsuz yönleri bu teknikle giderilmeye çalışılmış ve bir anlamda bazı durumlarda içinde diğer teknikleri de kapsar şekilde geliştirilmiştir. Newbold ve Granger [1] tarafından 50 seri üzerinde yapılan araştırmada, Box-Jenkins tekniğinin belli başlı diğer tekniklere göre daha güvenilir sonuçlar verdiği görülmüştür.

Box-Jenkins tekniği zaman serilerinin ileriye dönük tahminlerinde kullanılan tekniklerden biridir. Kısa dönem tahminlerde daha başarılı sonuçlar veren bu yöntem, zamana bağlı olarak elde edilen gözlem değerlerinden, kesikli ve durağan zaman serilerinin tahmin modellerinin kurulmasında ve bu modellerle tahminlerin gerçekleştirilmesinde kullanılır [2]. Tekniğin amacı en az sayıda parametre içeren uygun modeller elde etmektir [3]. Box-Jenkins tekniğine ait modeller zamana bağlı olayların tesadüfi yapıdaki olaylar olduğunu kabul etmekte [4] ve bu yönteme kadar geliştirilen diğer tekniklere göre önemli farklılıklar içermektedir. Zaman serisinin şimdiki ve geri dönem gözlem değerlerini kullanarak tahmin yapan Box-Jenkins'den önceki Hareketli Ortalama 
ve Üstel Düzeltme Teknikleri, bir tahmin fonksiyonu geliştirilip, tahmin değerleri uzman bilgisi olmadan otomatik olarak elde edilebilir. Bu yönden BoxJenkins tekniği tamamıla otomatik değildir ve diğer tekniklere nazaran oldukça karışık ve anlaşıııası da zordur [3] . Ayrica modelin belirlenmesi ve modelin parametrelerinin hesaplanması oldukça fazla zaman aldığı gibi, zaman serisinin de en az 60-70 gözlem içermesi ve bu teknikten iyi sonuç alınabilmesi için tahmini yapanların teorik bilgi ve tecrübe açısından yeterli olmaları gerekir [3] .

Box-Jenkins tekniği incelenen serilerin durağan olup olmamasına, mevsimlik etki içerip içermemesine göre farklı şekillerde tahmin modelleri geliştirmeye uygun bir yapıdadır [18]. Sözkonusu teknik beş aşamadan geçerek tahmin işleminin gerçekleştirilmesini amaçlamaktadır [5] . Bunlar; incelenen seri için genel model sınıfının belirlenmesi, genel modelin derecesinin belirlenmesi, parametre tahminleri, uygunluk testi ve tahmin işleminin gerçekleştirilmesidir. Box-Jenkins modelleri kullanıldığı alanlar yönünden birçok değişik kaynaklardan gelen verilere uygulanabilir.

Box-Jenkins tahmin tekniği; çözüme adım-adım gitmesi, her adımda denetlenebilmesi, istatistik testlerle sonuca ulaşması, incelenen verilerin özelliğine göre verileri modelleyebilmesi (model seçiminde serbestlik) gibi üstün özelliklerinden dolay1 tercih edilen bir teknikdir. Bu nedenle BoxJenkins modellerini kullanarak yapılacak kısa dönemli tahminlerin diğer tekniklerin kullanılmasiyla yapılacak tahminlerden daha güvenilir olacağı söylenebilir [6] . Bunun yanında sözkonusu tekniğe uygulama yönünden tenkitler yapılmaktadır. Chambers [7] ve arkadaşlarına göre diğer tekniklerle karşılaştırıldığında uygulama maliyeti en yüksek fakat kısa dönemde en iyi sonucu veren tahmin tekniği olarak Box-Jenkins gösterilmektedir. Yapılan tenkitler genel olarak beş noktada toplanabilir [3] ;

- Üssel Düzeltme tekniklerinde olduğu gibi BoxJenkins modellerinden tahmin çabucak elde edilemez.

- Box-Jenkins tekniği ile tahminde uygulamacının ihtisas sahibi olması zorunludur.

- Belirleme aşamasında tekniğin uygulamacıya tanıdığı geniş olanaklar en kötü seçimin yapılmasına dolayısıyla sağlıssı tahminlerin ortaya çıkmasına neden olabilir.

- Ayn zaman serisini kullanan iki uygulamacı sayısal olarak farklı sonuçlara varabilir. Bunu önleyici herhangi bir denetim sistemi yoktur.

- Başarılı bir uygulama için oldukça büyük örnekleme olmalıdır.

\subsubsection{Otoregresif Modeller (AR)}

$\mathrm{Bu}$ modeller bir zaman serisinin herhangi bir dönemindeki gözlem değerlerini, aynı serinin ondan önceki belirli sayıda dönemin (geçmiş dönemin) gözlem değerlerine ve hata terimine bağlı olarak açıklayan modellerdir. Başka bir deyişle, AR modeller bir zaman serisinin herhangi bir dönemindeki gözlem değerini, aynı serinin ondan önceki belirli sayıda dönemin gözlem değerinin ve hata teriminin doğrusal bir bileşimi olarak ifade eden modeldir.

AR modelleri içerdikleri geçmiş dönem gözlem değerleri sayısına göre isimlendirilirler. Yani bir AR modeli bir tane gözlem değeri içeriyorsa "birinci dereceden", iki tane geçmiş dönem gözlem değeri içeriyorsa "ikinci dereceden" ve genel olarak, $p$ tane geçmiş dönem gözlem değeri içeriyorsa p'inci dereceden AR modeli olarak isimlendirilir AR(p) [8] Uygulamada daha çok birinci ve ikinci mertebeden AR modelleri kullanılır ve sirasiyla AR(1) ve AR(2) olarak kısaltılarak simgelenirler [5] .

\subsubsection{Hareketli Ortalama Modelleri (MA)}

Hareketli Ortalama Modelleri, herhangi bir dönemdeki gözlem değerini, zaman serisinin aynı ve ondan önceki belirli sayıda dönemindeki hata terimlerine bağlı olarak açılayan modellerdir [8] . MA modelleri içerdikleri geçmiş dönem hata terimi sayısına göre isimlendirilirler. Eğer modelde bir tane geçmiş dönem hata terimi varsa birinci, iki tane varsa ikinci ve genel olarak q tane varsa q'uncu mertebeden MA modelleri olarak isimlendirilirler MA(q). Uygulamada daha çok birinci ve ikinci mertebeden MA modelleri kullanılır ve sirasiyla MA(1) ve MA(2) olarak kisaltılarak simgelenirler [5] .

\subsubsection{Birleştirilmiş Otoregresif-Hareketli Ortalama Modeli ARMA(p,q)}

Zaman serilerinin modellenmesinde esneklik sağlamak ve en az sayıda parametre ilkesini gerçekleştirmek amacıyla bazı durumlarda, modele hem otoregresif ve hem de hareketli ortalama parametrelerinin alınması bir çok yararlar sağlamaktadır. $\mathrm{Bu}$ düşünce $\operatorname{ARMA}(\mathrm{p}, \mathrm{q})$ modelini ortaya çıkarmıştır [3] . ARMA modelleri AR ve MA modellerinin bir karışımıdır. ARMA modellerinde herhangi bir zaman serisinin herhangi bir dönemine ait elde edilen gözlem değerleri, sözkonusu dönemden önceki belirli sayıdaki gözlem değeri ve hata teriminin doğrusal bir bileşimi olarak ifade edilir. ARMA modeli AR ve MA modellerinin karışımından meydana geldiği için $\mathrm{p}+\mathrm{q}+2$ adet terimden oluşur ve $(p, q)$ 'uncu mertebeden genel $\operatorname{ARMA}(\mathrm{p}, \mathrm{q})$ modeli şekilde yazılabilir. Bu modele 
ilişkin sembollerin anlamları $\mathrm{AR}(\mathrm{p})$ ve $\mathrm{MA}(\mathrm{q})$ modellerinde tanımlandığ modeli en genel doğrusal durağan stokastik modeldir. Çünkü ARMA(p,q) modelinde $p=0$ alınırsa MA(q) modeli, $q=0$ alınırsa $A R(p)$ modeli elde edilir. Yani $\operatorname{ARMA}(0, q)=M A(q) \quad$ ve $\operatorname{ARMA}(p, 0)=A R(p)$ dir. Başka bir deyişle $A R(p)$ ve MA(q) modelleri ARMA(p,q) modelinin özel bir halidir .Uygulamada sık karşılaşılan ARMA model türü $\operatorname{ARMA}(1,1)$ modelidir. $\mathrm{Bu}$ model birinci dereceden $(p=1)$ AR ve birinci dereceden $(q=1)$ MA modelinin kombinasyonudur [6] .

\subsubsection{Doğrusal Durağan Olmayan Stokastik Modeller (ARIMA)}

Buraya kadar, durağan olan zaman serileri analizinde kullanılan modeller tanitılmaya çalışılmıştır. Uygulamada zaman serilerinin bazılarının durağan olmadığı görülebilir. Bu seriler, daha öncede açıklandığı gibi zaman içinde ortalaması sabit olmayan dolayısıyla ortalaması önemli değişmeler gösteren serilerdir. Başka bir ifadeyle zaman serilerinin bazılarının zaman içerisinde, tesadüfi değişmenin yanında trend, konjonktür ve mevsimlik dalgalanma ve değişmeler de gösterdiği görülür. Durağan olmayan zaman serilerinde durağanlığ bozan etkilerin belirlenmesi ve yok edilmeleri gerekir. Bu tür durağan olmayan bir zaman serisi bazı işlemlerle durağan hale getirilebiliyorsa, yeni seriye ARIMA modelleri uygulanabilir.

Durağan olmayan bir zaman serisi, birbirini izleyen gözlem değerlerinin farkları alınması suretiyle durağan hale getirilebilir [9] . Bu şekilde elde edilen seri; birinci farkları alındıysa birinci farklar serisi, ikinci farkları alındıysa ikinci farklar serisi v.b. gibi isimlendirilir. Her fark alma işleminin sonunda serinin durağan olup olmadığı çeşitli testlerle belirlenir, durağan değilse aynı şekilde fark alma işlemine devam edilir. Genellikle uygulamada birinci veya ikinci farklar serisi durağan olarak elde edilebilmektedir. Durağan olmayan bir seride her zaman fark alma işlemi, serinin durağanlığını sağlaması için yeterli olmayabilir. Böyle durumlarda orijinal serinin tabii logaritmasını almak veya orijinal seriyi kuvvet fonksiyonu ile dönüşüm işlemine sokmak da mümkündür [10] [5] . Durağan hale getirilmiş farklar serisine ARMA modelleri uygulanır.

$\mathrm{Bu}$ modellere ARIMA (Autoregressive-Integrated Moving Average), Birleştirilmiş OtoregresifHareketli Ortalama Modelleri denir ve p, AR model mertebesini, d fark alma mertebesini, q MA model mertebesini ifade etmek üzere $\operatorname{ARIMA}(\mathrm{p}, \mathrm{d}, \mathrm{q})$ şeklinde gösterilir. Mevsimin etkisi altında olmayan $\operatorname{ARIMA}(\mathrm{p}, \mathrm{d}, \mathrm{q})$ modelinde $\operatorname{ARMA}(\mathrm{p}, \mathrm{q})$ modelindeki kadar hesaplanması gereken parametre vardır. $\operatorname{ARIMA}(\mathrm{p}, \mathrm{d}, \mathrm{q})$ modelinde $\mathrm{p}$ veya $\mathrm{q}$ sifir değerini alabilir. $\mathrm{Bu}$ durumda $\operatorname{ARIMA}(\mathrm{p}, \mathrm{d}, \mathrm{q})$ modeli $\operatorname{ARI}(d, p)$ veya IMA $(d, q)$ modeline indirgenmiş olur.

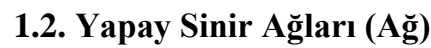

Yapay Sinir Ağları, biyolojik sinir sisteminden esinlenerek ortaya atılmış basit işlem elemanlarının bağlantılarından meydana gelen ve paralel bilgi işleme, örneklerden öğrenebilme, genelleştirme yapabilme gibi özellikleri olan bir bilgi işleme modelidir [11] [12]. Bu sistemler canlıların sinir sisteminin işleyişinden esinlenerek geliştirilmişlerdir [18]. Ağları oluşturan işlem elemanları, modellere göre değişen bir bağlantı tarzıyla birbirlerine bağlanarak modelin yapısını oluştururlar. Yapay Zeka teknikleri içerisinde en çok ilgi bulan ve kullanım alanını genişleten tekniklerden olması, Yapay Sinir Ağlarının hesaplama sisteminin hızlılı̆̆ ve kolaylığı, eksik, bulanık ve belirsiz bilgiyi rahatlıkla işleyebilme ve bu bilgilerle de olumlu çözüm üretebilme özelliklerine dayanır [13] [17] [19] .

Literatürde çok geniş bir uygulama alanına sahip olan Yapay Sinir Ağları, tahminden robot kontrolüne, örüntü tanımadan medikal elektroniğe kadar bir çok uygulama örneklerinde de görülebilen başarısını ispatlamıştır [19]. Örneğin örüntü tanımada Öztemel [13] , Hwarng ve Hubele [14] istatistiksel proses kontrolünde kullanılan kontrol diagramlarının tanınıp yorumlanmasında Yapay Sinir Ağları ile başarılı uygulamalar sergilemişlerdir. Yapay Sinir Ağlarının bütün bu başarısının yanında en önemli dezavantajı, üretilen bilginin neden ve nasıl üretildiği konusunda bir açıklamada bulunamaması sayılabilir [15-16] .

\section{Uygulama ve Bulgular}

Çalışma için Box-Jenkins tekniğine ait günlük hayatta en çok kullanılan $\operatorname{AR}(1), \operatorname{AR}(2), \operatorname{MA}(1)$, MA(2), ARMA(1,1) modelleri seçilmiş ve durağan olmayan seriler için de en fazla ikinci fark serisinin durağanlığ 1 sağlayacağı kabul edilmiştir. Geliştirilen algoritmada bu modeller AR(1), MA(1), RANDOM ve $\operatorname{AR}(2), \operatorname{MA}(2), \operatorname{ARMA}(1,1)$ olarak iki gruba ayrılmış ve bilgisayar tarafından gruplardan seçilen birer model içinden en düşük ortalama mutlak tahmin hatasını verecek modelin incelenen seri için uygun model olacağı kabul edilmiştir. İncelenen serinin durağanlığı ve kurulan modelin tahmin için kullanılıp kullanılamıyacağı Q testi (Portmanto testi) ile kontrol edilmiştir.

Çalışmanın amacı; Box-Jenkins tekniği ile elde edilen tahmin sonuçlarına Yapay Sinir Ağları tarafindan eğitilen ağlar ile ne kadar 
yaklaşllabileceği olarak belirlenmiştir. $\mathrm{Bu}$ doğrultuda Box-Jenkins tekniğinin çözüme giderken kullandığı aşamalardan, incelenen serinin model ve derecesinin belirlenmesi ve belirlenen model ve dereceye uygun parametrelerin tahmin edilmesi adımları yerine, bu amaçla eğitilmiş ağların kullanılması ve iki yönteme göre elde edilen sonuçların kıyaslanması düşünülmüştür. Bu nedenle gerekli yerlerde eğitilmiş ağlara ait ağırlık dosyalarını kullanan bir algoritma geliştirilmiş ve bu algoritma bir bilgisayar yazılımı haline getirilerek hem düşünülen yapının otomatize edilmesi hem de çalışma sırasında işlemlerin tarafımızdan çabuklaştırılması sağlanmıştır. Çalışmanın asıl amacı bir yazılım geliştirmek olmayıp algoritmanın geliştirilmiş olması bizim için yeterlidir. Fakat düşünülen yapıya uygun algoritmanın bilgisayar yazılımı haline getirilmesi, başlangıçta çalışma için çizilen çerçevenin bir adım ötesine gidilmesi olarak değerlendirilmelidir.

Kıyaslama, içinde eğitilmiş ağları kullanan yazılım ile, çözüme giderken tahmincinin bilgisine ihtiyaç duyan Statistica for Windows programı sonuçlarına göre yapılmıştır. Statistica programı ile çözüme gidilirken Box-Jenkins tekniğine ait adımlar kullanılmış, karar verilmesi gereken noktalara tahminci (uzman) olarak tarafimızdan müdahale edilmiştir. Geliştirilen algoritma da çözüme BoxJenkins tekniğine ait adımlarla gitmesine rağmen, eğitilmiş ağları belirli adımlarda karar verici olarak kullandığından dolayı otomatik bir şekilde çalışmakta ve uzman bilgisine gerek duymamaktadır.

\subsection{Model Seçimi ve Derecesinin Belirlenmesi için Yapay Sinir Ağlarının Eğitilmesinden Elde Edilen Sonuçlar}

Çalışmada, belirlenen 5 modele ait model seçimi ve derecesinin belirlenmesi için sözkonusu modeller 2 grup halinde düşünülerek herbir gruba ait birer adet ağ eğitilmiş ve test edilmiştir. Eğitilen ağlara ait bilinen ve elde edilen bazı bilgiler aşağıya çıkarılmıştır.

- Çalışmada Yapay Sinir Ağı olarak "Öğretmenli Hataları Geri Yayma (Back Propagation) Algoritması" kullanılmıştır.

- Kurulan herbir ağın eğitilmesi ve test edilmesi için, seçilen serilere ait belli sayıda sırasıyla otokorelasyon ve kismi otokorelasyonlardan meydana gelen girdiler tanıtılmıştır.

- Çıktı değerleri 1 ve 0 değerlerinden meydana gelen sayılarla sinıflandırılmıştır.

- Öğrenme seti, girdiyi oluşturan modellere ait otokorelasyon ve kısmi otokorelasyon değerlerinin belli düzende karıştırılması ile oluşturulmuştur. Aynı durum çıktı seti için de geçerlidir. Buna göre, girdi ve çıktı belli düzende karıştırılarak veya herhangi bir kural gözetilmeden karışık olarak farklı ağlarda ve çeşitli defalarda denenmiş, uygun sonuçlar girdi ve çıktının belli düzende karıştırıldığ 1 ağlarda elde edilmiştir.

- Oluşturulan ağlar, küçük sayılardaki ara katman değerlerinde istenen sonuçları vermiştir. Daha sonra görüleceği üzere, parametre tahminlerinde istenen sonuçlara büyük ara katman değerleriyle ulaş̧labilmiştir.

- Eğitilen ağın seçilen test setleri ile işleme sokulmasından $\% 100$ başarı sağlanmıştır. Bu sonuç, mevsimlik etki göstermeyen ve durağanlık şartına uyan serilerin eğitilen ăg tarafindan model ve derecesinin doğru bir şekilde belirlenebileceğini göstermektedir.

\subsection{Parametre Tahmini ve Nihai Tahmin Sonuçlarının Değerlendirilmesi}

Çalışmamızda, belirlenen 5 modele ait parametre değerlerinin tahmini için yine 5 adet her modele ait ağ eğitilmiş ve test edilmiştir. Ayrıca eğitilen ağdan elde edilen parametre değerleriyle nihai tahminler gerçekleştirilmiştir. Eğitilen ağlara ve nihai tahminlere ait bilinen ve elde edilen bazı bilgiler aşağıya çıkarılmıştır.

- Herbir ağı eğitme ve test etme için, seçilen serilere ait belli sayıda otokorelasyon ve/veya k1smi otokorelasyonlardan meydana gelen girdiler tanıtılmıştır. Belirlenen 5 modelden sadece $\operatorname{ARMA}(1,1)$ için kısmi otokorelasyon değerleri, diğer 4 model için sırasıyla otokorelasyon ve kısmi otokorelasyonlardan meydana gelen seriler isteğe yakın parametre değerlerinin elde edilmesi için en uygun sonucu vermiştir.

- Parametre tahminleri için oluşturulan ağlar, model ve derecesinin belirlenmesinde kullanılan ağlara göre ARMA(1,1) modeli hariç, büyük sayılardaki ara katman değerlerinde istenen sonuçları vermiştir. Eğitilen ağlara ait en küçük hatalı parametre tahmin değerleri, herbir model için aynı öğrenme (0.3) ve momentum (0.8) katsayılarılya elde edilmiştir. $\mathrm{Bu}$ iki değer haricinde değişik katsayılarda denemeler yapılmışsa da, istenen sonuçlara ulaşılamamıştır.

- Parametre tahminlerinde eğitilen ağlara ait en büyük ortalama mutlak hata $\operatorname{ARMA}(1,1)$ modelinde, en küçük hata $\mathrm{AR}(1)$ modelinde elde edilmiștir. Diğer modellerin hataları AR(1)'e yakın değerlerden oluşmaktadır. $\operatorname{ARMA}(1,1)$ modelinin parametre tahmin hatalarının düşürülmesi için değişik otokorelasyon ve kısmi otokorelasyon sayılarında denemeler yapılmış, öğrenme ve momentum katsayıları, ara katman sayıları değiştirilmiş, öğrenme setine ait orijinal serinin ağa tanttılması denenmiş fakat yukarıda elde edilen hata değerinden 
daha küçük değer elde edilememiştir.Belirlenen 5 model ve iki yönteme göre, nihai tahminlerin ortalama mutlak hataları birbirine çok yakın değerler olarak elde edilmiştir. Bu sonuç herbir modele göre eğitilen ağın, sözkonusu 5 modelin parametreleri açısından iyi bir tahmin edicisi olduğunu göstermektedir.

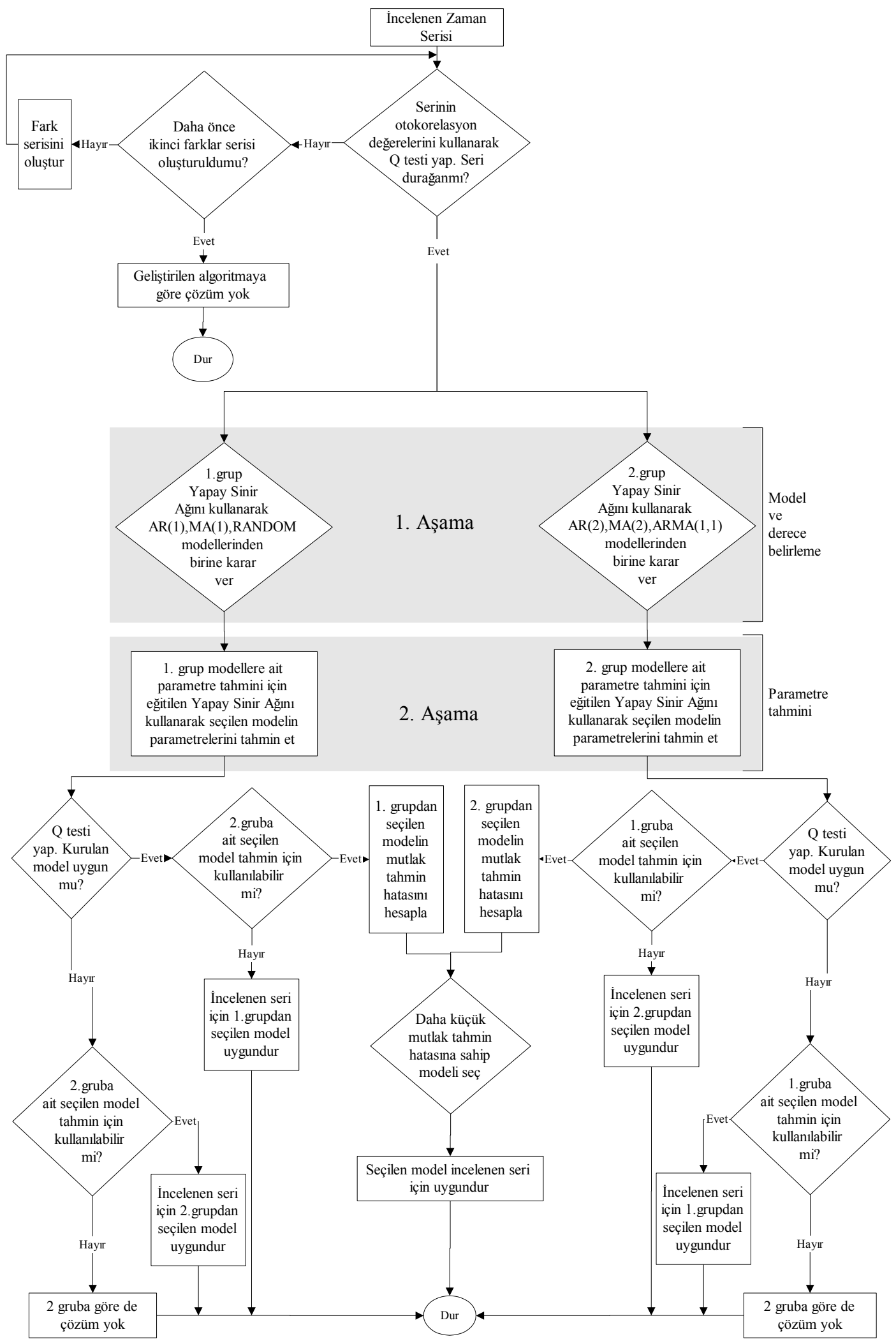

Şekil 1. Geliştirilen algoritmaya ait akış diagramı 
- Nihai tahminlerin ortalama mutlak hata değerlerine göre de en yüksek hata $\operatorname{ARMA}(1,1)$ modelinde, en düşük hata $\mathrm{AR}(1)$ modelinde elde edilmiştir. $\mathrm{Bu}$ durumun ARMA $(1,1)$ modelinin kendisini oluşturan iki modelin de ortak özelliklerine beraberce sahip olduğundan ve dolayısıyla eğitilen ağ tarafindan kolayca ayırt edilememesinden kaynaklandığ1 düşünülmektedir.

$-$

- Modellerin daha fazla sayıdaki parametre ile temsil edilmesi, hem eğitilen ăg ve hem de Statistica programındaki parametre tahmin değerleri ve nihai tahmin değerlerinin hatalarını arttırmaktadır. $\mathrm{Bu}$ sonuç, "Box-Jenkins modellerinin mümkün olan en az sayıda parametre ile temsil edilmesi” gerektiği tezini doğrulamaktadır.

\subsection{Geliştirilen Algoritmanın 5 modele Ait Test Setleriyle Işleme Sokulmasından EIde Edilen Sonuçlar}

- Her model geliştirilen algoritma tarafindan diğer 4 modele göre başarılı bir şekilde ayırt edilebilmektedir.

- 5 modele göre ayrı ayrı oluşturulan test setlerinin geliştirilen algoritma ile işleme sokulmasından elde edilen başarı \%100'dür. Her test serisi olması gereken modele göre uygun bir şekilde sonuçlanmıştır. Bu durum, Box-Jenkins tekniğindeki model ve derecesinin seçimi ve kurulan modelin parametrelerinin tahmini için Yapay Sinir Ağlarının kullanılabileceğini göstermektedir.

- Box-Jenkins tahmin tekniği tarafından iddia edilen, "yüksek derecede modellenebilen AR, MA ve ARMA modellerinin daha düşük derecelerdeki modellerin özelliklerini de gösterdikleri, ayrıca ARMA modelinin kendisini oluşturan AR ve MA modellerinin özelliklerini üzerinde taşıdığı" görüşü, geliştirilen algoritmadan elde edilen sonuçlarda görülebilmektedir.

\section{4. Örnek Çalışmadan Elde Edilen Sonuçlar}

- Uygulama için seçilen X işletmesinden elde edilen verilerle oluşturulan 3 serinin durağan olmaması, 1 'inci farklarla durağan hale getirilmesi ve MA(1) modeline uygun olması, çalışmanın çerçevesine uygun düşmektedir. Çünkü çalışmanın çerçevesi günlük hayatta en çok karşılaşılan durumlara göre belirlenmişti. Buna göre, günlük hayattan elde edilen verilerle oluşturulan serilerin çoğunlukla durağan olmadıkları, durağan olmayan serilerin en çok 2'inci farklarının alınmasıyla durağan hale getirilebildiği ve yine bu serilerin $\mathrm{AR}(1), \mathrm{AR}(2), \mathrm{MA}(1), \mathrm{MA}(2)$ veya $\operatorname{ARMA}(1,1)$ modellerinden birisine uyduğu kabul edilmişti.
- Box-Jenkins tekniğinin doğru bir şekilde sonuç verebilmesi için diğer tahmin tekniklerine göre oldukça fazla sayıda veri ile çalışma kısıtı vardır. Çalışma, 80 elemanlı serilerle Box-Jenkins yönteminde tahmin yapılabileceğini göstermiştir. Özellikle ağlarla ilgili eğitme ve test işlemleri sırasında ve çalışmanın uygulama bölümünde, serideki elemanların yetersizliğinden kaynaklanan bir problemle karşılaşılmamıştır.

- Statistica programı ile elde edilen tahminlerin geliştirilen algoritmadan elde edilen tahminlere göre onbinde mertebesinde daha iyi sonuç vermesine rağmen, geliştirilen algoritma tahminci ve bilgisayar maliyeti açısından tercih edilebilir. $\mathrm{Bu}$ durumda algoritma ile elde edilen hata değerinin maliyeti, diğer yöntemi kullanmak için gerekli tahminci ve bilgisayar maliyeti ile kiyaslanması gerekir. Algoritmanın çalıştırılması neticesinde ortaya çıkan hata maliyeti katlanılabilir ölçülerdeyse, geliştirilen algoritmanın kullanılması daha akılcı olacaktır. Çünkü Statistica programı, Box-Jenkins tekniğini uygulayabilen ve bilgisayar kullanım maliyetini düşürebilecek bir tahminciye ihtiyaç duymaktayken, geliştirilen algoritma için böyle bir zorunluluk yoktur.

\section{Sonuç}

$\mathrm{Bu}$ çalışmada Box-Jenkins tekniğinin çözüme giderken kullandığı adımlar yerine Yapay Sinir Ağları kullanılmış ve genel anlamda iki grup ağ eğitilmiştir. Birinci grup eğitilen ağ incelenen serinin model ve derecesini belirlemeye yönelik olup bu aşamada eğitilen ağların karar verici olarak kullanılması düşünülmüştür. Çünkü bilinen şekliyle bu aşamada tahmini yapan kişinin insiyatifinin devreye girmesi gerekirken, geliştirilen algoritmada bu aşama için tahmini yapan kişinin bilgi, tecrübe ve sezgilerinin aktarıldı̆̆ sokulmaktadır. İkinci grup eğitilen ağ, parametre tahminine yönelik olup Box-Jenkins tekniğine ait sözkonusu adımdaki hesaplama güçlüğüne bir alternatif olarak düşünülmüştür. Bu amaçla çalışma için seçilen 5 modelin herbirine ait birer ağ eğitilmiş ve test edilmiştir. Birinci ve ikinci grup ağlar için eğitme ve test işlemleri 80 elemanlı seriler üzerinden gerçekleştirilmiştir.

Model ve derece belirleme ve parametre tahminleri için oluşturulan öğrenme ve test setleri için Statistica programından elde edilen değerler esas alınmıştır. İncelenen seriye ait otokorelasyon ve/veya kismi otokorelasyon grafiklerinin, Yapay Sinir Ağları tarafindan model ve derece belirleme ve parametre tahminlerinin yapılabilmesi açısından uygun olabileceği düşünülmüş ve eğitme işlemlerinin sonucunda bu düşüncenin doğruluğu kanıtlanmıştır. Buna göre yapılan denemelerde birinci grup 
modeller için 4'er, ikinci grup modeller için 6'şar adet otokorelasyon ve k1smi otokorelasyon katsayılarının incelenen seriye ait model ve derecesini belirlemek için yeterli olduğu sonucu elde edilmiştir. Her iki gruba ait oluşturulan test setlerinden elde edilen başarının \%100 olduğu görülmüştür. Parametre tahminleri için modellere göre AR(1) için 6'şar, MA(1) için 6'şar, AR(2) için 6'şar, MA(2) için 10'ar adet otokorelasyon ve kısmi otokorelasyon, $\operatorname{ARMA}(1,1)$ için sadece 10 adet kısmi otokorelasyon katsayısının eğitilen ağ için yeterli olduğu görülmüştür.
Son olarak geliştirilen algoritma ve Statistica program $1 \mathrm{X}$ işletmesinden elde edilen gerçek verilere ait 3 seri için ayrı ayrı çalıştırılmıştır. 3 seriye ait model ve derece iki yönteme göre de MA(1) olarak bulunmuştur. Birer dönem sonrası için her iki yönteme göre elde edilen tahmin sonuçları ve gerçekleşmiş değerlere göre yöntemlerin tahmin hata yüzdeleri aşağıya çıkarılmıştır. Üçüncü seri için gerçekleşmiş değer elde edilemediğinden, sözkonusu seri için tahmin hata yüzdesi hesaplanamamıştır.

Tablo 1: Sonuçların karşılaştırılması

\begin{tabular}{|l|l|l|l|l|l|}
\hline $\begin{array}{l}\text { Seri } \\
\text { No }\end{array}$ & $\begin{array}{l}\text { Gerçekleşmiş } \\
\text { değer (Aylık) }\end{array}$ & $\begin{array}{l}\text { Statistica } \\
\text { programından } \\
\text { elde edilen } \\
\text { tahmin değeri }\end{array}$ & $\begin{array}{l}\text { Geliştirilen } \\
\text { algoritmadan } \\
\text { elde edilen } \\
\text { tahmin değeri }\end{array}$ & $\begin{array}{l}\text { Statistica } \\
\text { programindan } \\
\text { elde edilen } \\
\text { tahminin hata } \\
\text { yüzdesi }\end{array}$ & $\begin{array}{l}\text { Geliştirilen } \\
\text { algoritmadan } \\
\text { elde edilen } \\
\text { tahminin hata } \\
\text { yüzdesi }\end{array}$ \\
\hline 1 & 82324 & 70349.28 & 70342.12 & 14.546 & 14.556 \\
\hline 2 & 73040 & 74225.20 & 74277.76 & -1.623 & -1.695 \\
\hline 3 & ------- & 73748.03 & 73762.83 & ------- & ------- \\
\hline
\end{tabular}

Yukarıdaki sonuçlara göre, geliştirilen algoritmadan elde edilen tahmin değerleri, Statistica programından elde edilen tahmin değerlerine göre çok küçük say1labilecek değerde daha kötü sonuç vermesine rağmen, geliştirilen algoritmanın tahmini yapan (uzman) ve bilgisayar maliyetleri açısından tercih edilebileceğini göstermektedir.

\section{Kaynaklar}

[1] P. Newbold and C.W.J. Granger, "Experience with Forecasting, Univariate Time Series and the Combination of Forecast", Journal of Royal Statistical Society, Vol.37, p.75, 1974.

[2] V.A. Mabert and R.C. Radcliffe, "A Forecasting Methodology as Applied to Financial Time Series", The Accounting Review, Vol.49, p.62, 1974.

[3] H. Kaya, "İstatistiksel Ön Tahmin Yöntemleri", Ankara H.Ü. İkt. ve İd. Bil. Fak. Yayınları, 1985.

[4] G.E.P. Box, and G.M. Jenkins, "Time Series Analysis: Forecasting and Control", California Holden-Day Inc., 1976.

[5] S. Makridakis, S.C. Wheelwright and V.E. McGee, "Forecasting: Methods and Application", New York Jhon Wiley \& Sons, 1983.

[6] A. Özmen, "Mevsimsel Dalgalanmalar İçermeyen Zaman Serilerinde Kısa Dönem Öngörü Amaçlı Box-Jenkins (ARIMA) Modellerinin Kullanımı", Anadolu Üniv. Fen-Edebiyat Fakültesi Dergisi (Istatistik), C:2, No.1, s.106, 1989.

[7] J. C. Chambers, S.K. Mullick and D.D. Smith, "How to Choose the Right Forecasting Technique", Harvard Business Review, pp.45-74, 1971.

[8] T.H. Naylor, T.G. Seaks and D.W. Wichern, "Box-Jenkins Methods: An Alternative to
Econometric Models", International Statistical Review, Vol.40, s.125, 1972.

[9] L.A. Johnson and D.C. Montgomery, "Operations Research in Production Planning, Scheduling and Inventory Control", New York John Wiley \& Sons Inc., p.466, 1974.

[10] D.C. Montgomery and L.A. Johnson, "Forecasting and Time Series Analysis", New York McGraw-Hill, p.206, 1976.

[11] K.J. Hunt, D. Sbarbaro, R. Zbikowski and P.J. Gawthrop, "Neural Network for Control System-A Survey", Automatica, Vol:28, No:6, pp.1083-1112, 1992.

[12] T. Fukuda and T. Shibata, "Theory and Applications of Neural Networks for Industrial Control Systems", IEEE Trans. on Industrial Electronics, Vol:39, No:6, pp.472-489, 1992.

[13] E. Öztemel, 'Integrating Expert Systems and Neural Networks for Intelligent on-line Statistical Process Control", PhD Dissertation, University of Wales, 1992.

[14] H.B. Hwrang and N.F. Hubele, "X-Bar Chart Pattern Recognition Using Neural Nets", In: 45th Annual Quality Congress. American Society for Quality Control, Milwaukee, pp.884-889, 1991.

[15] D.T. Pham and E. Öztemel, "An Integrated Neural Network and Expert System Tool For Statistical Process Control", Proc. Mech. Engrs, Vol:209, pp.91-97, 1995.

[16] S.K. Sim, K.T. Veo and W.H. Lee, "An Expert Neural Network System for Dynamic Job Shop Scheduling", Int.J. Prod.Res., Vol:32, No:8, pp.1759-1773, 1994.

[17] E. Öztemel, "Yapay Sinir Ağları", Papatya Yayıncılık, İstanbul, 2003. 
[18] O. Kaynar, S. Taştan, "Zaman Serisi Analizinde MLP Yapay Sinir Ağları ve ARIMA Modelinin Karşılaştırılması", Erciyes Üniversitesi İktisadi ve İdari Bilimler Fakültesi Dergisi, Say1:33, ss.161172, 2009.
[19] A. Ötkün, B. Karlık, "YSA ve Pencere Ortalamarı Kullanılarak Yüz Tanıma Sistemi”, Otomatik Kontrol Ulusal Toplantısl, ss.996-1000, 2013. 